\title{
PENGEMBANGAN SOAL OPEN ENDED UNTUK MENGUKUR KEMAMPUAN BERPIKIR KREATIF SISWA PADA MATERI LINGKARAN KELAS VIII SMP NEGERI 9 KOTA JAMBI
}

\author{
Rani Ulandari ${ }^{1}$, Hasan Basri Said ${ }^{2}$, Eni Defitriani ${ }^{3}$ \\ Mahasiswa Pendidikan Matematika, FKIP, Universitas Batanghari, Jambi ${ }^{1}$ \\ Dosen Pendidikan Matematika, FKIP Universitas Batanghari, Jambi ${ }^{2,3}$ \\ E-mail : $\underline{\text { raniulandari9@gmail.com }}$
}

\begin{abstract}
ABSTRAK
Penelitian ini merupakan penelitian pengembangan yang bertujuan untuk menghasilkan produk berupa soal open ended untuk mengukur kemampuan berpikir kreatif siswa pada materi lingkaran yang valid dan reliabel. Penngembagnan soal open ended ini sesuai dengan kurikulum yang berlaku. Dengan demikian diharapkan dapat memperkaya bahan ajar yang ada. Penelitian ini merupakan penelitian Research and Development (R\&D) menggunakan model pengembangan ADDIE yang meliputi lima tahap yaitu; analysis (analisis), design (perancangan), development (pengembangan), implementation (implementasi), evaluation (evaluasi). Subjek penelitian ini adalah siswa kelas VIII SMP Negeri 9 Kota Jambi. Instrumen yang digunakan dalam penelitian berupa (a) lembar validasi untuk ahli materi, (b) angket respon siswa yang berfungsi untuk menentukan kevalidan soal, dan (c) soal open ended berfungsi untuk menentukan kevalidan, reliabilitas, tingkat kesukaran dan daya beda soal. Penelitian ini telah menghasilkan 5 soal open ended pokok bahasan lingkaran. Hasil uji validitas menunjukkan soal open ended yang dikembangkan valid yang dilihat dari persentase hasil perhitungan lembar validasi ahli materi yaitu $87 \%$, uji perorangan yaitu $87 \%$, uji kelompok kecil yaitu $93 \%$. Soal nomor 1, validitasnya adalah 0,62 , reliabilitas 0,6375 , tingkat kesukaran 0,88 , daya beda 0,21 . Soal nomor 2 dengan validitas 0,85 , reliabilias 0,6375 , tingkat kesukaran 0,78 , daya beda 0,41 . Soal nomor 3 dengan validitas 0,63 , reliabilitas 0,6375 , tingkat kesukaran 0,50 , daya beda 0,50 . Soal nomor 4 dengan validitas 0,70 , reliabilitas 0,6375 , tingkat kesukaran 0,86 , daya beda 0,21 . Soal nomor 5 dengan validitas 0,38 , reliabilitas 0,6375 , tingkat kesukaran 0,54 , daya beda $0,27.2$ soal dikategorikan terpakai 2 soal dikategorikan soal diperbaiki dan 1 soal tidak terpakai.
\end{abstract}

Kata Kunci : Berpikir Kreatif ; Soal Open Ended.

\begin{abstract}
This research is a research development that aims to produce products in the form of open ended questions to measure students' creative thinking abilities on valid and reliable circle material. Development of open ended questions is in accordance with the applicable curriculum. Thus it is expected to enrich existing teaching materials. This research is a Research and Development $(R \& D)$ study using the ADDIE development model which includes five stages namely; analysis (analysis), design (design), development (development), implementation (implementation), evaluation (evaluation). The subjects of this study were eighth grade students of SMP Negeri 9 Jambi City. The instruments used in the study were (a) validation sheets for material experts, (b) student questionnaire responses that function to determine the validity of the questions, and (c) open ended questions function to determine the validity, reliability, level of difficulty and different power of the questions. This research has produced 5 open ended questions on circle subjects. The results of the validity test show that the open ended questions developed are valid as seen from the percentage results of the material expert validation calculation that is $87 \%$, individual test that is $87 \%$, small group test that is $93 \%$. Problem number 1 , validity is 0.62 , reliability 0.6375 , difficulty level 0.88, difference power 0.21. Problem number 2 with validity 0.85 , reliability 0.6375 , difficulty level 0.78 , difference power 0.41. Problem number 3 with validity 0.63 , reliability 0.6375 , difficulty level 0.50, power difference 0.50. Problem number 4 with validity 0.70, reliability 0.6375, difficulty level 0.86, difference power 0.21. Problem number 5 with validity 0.38 , reliability 0.6375, difficulty level 0.54, power difference 0.27. 2 questions categorized as used 2 questions categorized as corrected questions and 1 unused question.
\end{abstract}

Keywords : Circles ;Creative Thinking; Open Ended Questions. 


\section{PENDAHULUAN}

Matematika merupakan salah satu mata pelajaran yang dipelajari disetiap jenjang pendidikan mulai dari tingkat sekolah dasar sampai perguruan tinggi. Melihat pentingnya matematika dan peranannya dalam menghadapi kemajuan ilmu pengetahuan dan teknologi serta persaingan global maka peningkatan mutu pendidikan matematika di semua jenis dan jenjang pendidikan harus selalu diupayakan (Wahyuni dan Abadi, 2014:1), maka dari itu diperlukan bahan ajar yang dapat membantu peserta didik dalam proses pembelajaran. Salah satu bahan ajar yang digunakan adalah soal.

Pembelajaran matematika yang dapat memberikan keleluasaan kepada siswa untuk berpikir secara aktif dan kreatif, salah satunya adalah pembelajaran dengan pemberian soal-soal open-ended .Salah satu tipe pemecahan masalah yang dapat meningkatkan kemampuan berpikir kreatif siswa adalah dengan cara siswa untuk memecahkan suatu masalah dengan menggunakan lebih dari satu cara penyelesaian dan tidak menutup kemungkinan siswa akan memperoleh jawaban.

Berdasarkan wawancara dengan guru mata pelajaran matematika yang mengajar di kelas VIII SMP Negeri 9 Kota Jambi mengatakan bahwa rendahnya berpikir kreatif siswa dapat disebabkan oleh siswa kurang memperhatikan guru mengajar, dalam pemberian soal guru menggunakan soal-soal yang ada dibuku paket atau LKS, guru juga belum pernah memberikan soalsoal yang bersifat terbuka atau soal open ended, setiap selesai menjelaskan materi, guru memberikan soal yang bersifat rutin.

Oleh karena itu perlu dikembangkan soal open ended untuk mengukur kemampuan berpikir kreatif siswa pada materi lingkaran Kelas VIII SMP Negeri 9 Kota Jambi. Bertujuan untuk menghasilkan produk berupa soal open ended untuk mengukur kemampuan berpikir kreatif siswa pada materi lingkaran yang valid dan reliabel.

\section{METODE PENELITIAN}

Penelitian ini merupakan penelitian pengembangan (Research and Development) yang bertujuan untuk mengembangkan perangkat pembelajaran berupa soal open ended pada materi lingkaran.

Desain penelitian pengembangan ini menggunakan model pengembangan ADDIE, meliputi lima tahap yaitu: (1) Tahap Analisis(Analysis); (2) Tahap Desain (Design);(3) Tahap Pengembangan (Development); (4) Tahap Implementasi (Implementation); dan (5) Tahap evaluasi (evaluation). Langkah-langkah pada tahap analisis meliputi analisis kurikulum, analisis karakteristik siswa dan analisis materi. Pada tahap desain ini kegiatan yang dilakukan yaitu, persiapan pembuatan produk, penyusunan kerangka dasar soal, dan penyusunan instrumen penilaian. Tahap Pengembangan merupakan tahap yang dilakukan dengan membuat produk soal. Kemudian pada tahap ini juga melakukan validasi dan uji coba perorangan dan uji coba kelompok kecil terhadap soal. Soal divalidasi ahli materi yang bertujuan untuk mengetahui kualitas soal open ended pada aspek kevalidan, reliabilitas, tingkat kesukaran soal dan daya beda soal. Sedangkan pada tahap pelaksanaan kegiatan yang dilakukan yaitu melakukan uji coba produk yang dikembangkan. Uji coba produk bertujuan untuk mengetahui kualitas soal open ended dari aspek kevalidan, reliabilitas, tingkat kesukaran soal dan daya beda soal dapat diperoleh dari hasil belajar siswa menggunakan soal yang dikembangkan.

Tahap evaluasi ini dilakukan pada setiap tahap mulai dari analisis, desain, pengembangan, dan implementasi. Evaluasi dalam penelitian adalah untuk melakukan 


\section{$\pi$ (Phi)}

revisi sehingga pada tahap evaluasi akhir diperoleh soal yang layak untuk digunakan dalam proses pembelajaran yang telah divalidasi oleh tim ahli.

Data yang diperoleh dari penelitian ini berupa data kuantitatif dan data kualitatif. Data kuantitatif merupakan data yang berwujud angka sebagai hasil observasi atau pengukuran Widoyoko (2015:21). Data kuantitatif tersebut diperoleh dari: (1) hasil validasi soal oleh validator; (2) hasil angket penilaian oleh siswa. Dalam pengumpulan ketiga data tersebut digunakan beberapa instrumen penelitian, yaitu (1) Lembar validasi soal; (2) lembar angket respon siswa; dan (3) tes hasil belajar siswa.

Data kualitatif, yaitu data yang disajikan dalam bentuk kata-kata bukan dalam bentuk angka. Data kualitatif ini berupa masukan/komentar yang diperoleh dari hasil validasi oleh ahli materi, ahli media, ahli desain dan angket respon siswa.

\section{HASIL DAN PEMBAHASAN}

Hasil penelitian ini membahas mengenai hasil dari setiap tahap pada model yang digunakan dalam mengembangkan soal open ended untuk siswa SMP kelas VIII, ialah model ADDIE. Tahap pada model ADDIE meliputi tahap analisis (analysis), tahap desain (design), tahap pengembangan (development), tahap pelaksanaan (implementation) dan tahap evaluasi (evaluation).

Tahap analisis(analysis) terdiri dari analisis kurikulum, analisis karakteristik peserta didik dan analisis materi. Pada tahap ini diperoleh dengan wawancara terhadap guru matematika di SMPN 9 Kota Jambi dan hasil analisis dokumen. Dari hasil anlisis dokumen dan wawancara terhadap guru matematika diperoleh bahwa kurikulum yang digunakan di SMPN 9 ialah kurikulum 2013. Karakteristik siswa SMPN 9 diperoleh bahwa kemampuan berpikir siswa ada yang tinggi dan rendah ada yang kreatif dan tidak kreatif . Hasil wawancara terhadap guru matematika diketahui materi lingkaran dapat disampaikan dengan memebrikan soal yang bersifat terbuka karena materi ini dapat dikaitkan dengan kehidupan sehari-hari.

Tahap desain (design) terdiri dari persiapan pembuatan produk, penyusunan kerangka dasar soal dan penyusunan instrumen penilaian. Pada tahap ini dilakukan dengan cara mengumpulkan beberapa referensi yang relevan dengan materi lingkaran yang akan digunakan dalam menyusun soal open ended yang diambil dari beberapa sumber dan sebagai acuan pembuatan kerangka dasar soal yang terdiri dari petunjuk pengerjaan soal, soal dan lembar jawaban siswa. Tahap desain ini dilakukan juga dengan membuat kisi-kisi angket dan pernyatan-pernyataan yang akan dituangkan dalam angket sesuai dengan yang dibutuhkan pada aspek penilaian.

Tahap pengembangan (development) yang dilakukan ada 3 yaitu, pembuatan produk soal, validasi dan revisi Adapun hasil validasi soal dapat dilihat pada Tabel 1 Tabel 1. Rekapitulasi Hasil Validasi oleh telaah pakar

\begin{tabular}{|c|c|c|c|c|}
\hline Ahli & $\begin{array}{c}\text { Aspek } \\
\text { Penilaian }\end{array}$ & $\begin{array}{c}\text { Rata- } \\
\text { rata }\end{array}$ & Persentase & Kriteria \\
\hline \multirow[t]{3}{*}{ Materi } & Isi & 4,40 & $88 \%$ & $\begin{array}{l}\text { Sangat } \\
\text { Layak }\end{array}$ \\
\hline & $\begin{array}{l}\text { Konstruk/ } \\
\text { penyajian }\end{array}$ & 4,42 & $88,4 \%$ & $\begin{array}{l}\text { Sangat } \\
\text { Layak }\end{array}$ \\
\hline & Bahasa & 4,20 & $84 \%$ & $\begin{array}{l}\text { Sangat } \\
\text { Layak }\end{array}$ \\
\hline \multicolumn{2}{|c|}{ Total Keseluruhan } & 4,34 & $87 \%$ & $\begin{array}{l}\text { Sangat } \\
\text { Layak }\end{array}$ \\
\hline
\end{tabular}

Berdasarkan rekapitulasi hasil validasi oleh validator, diperoleh persentase keseluruhan validasi oleh ahli materi $87 \%$. Sehingga soal open ended dinyatakan valid.

Setelah soal open ended selesai divalidasi oleh validator ahli materi tahap selanjutnya adalah melakukan uji coba soal. Sehingga uji coba yang dilakukan pada soal open ended yaitu Uji coba perorangan (one to one learner) dan uji coba kelompok kecil (samll group trial). Hasil uji coba soal dapat dilihat pada Tabel 2. 
Tabel 2. Hasil Uji Coba Soal Open Ended

\begin{tabular}{llccc}
\hline \multicolumn{1}{c}{ Uji Coba } & \multicolumn{1}{c}{ Pernyataan } & Rata-rata & Persentase & Kriteria \\
\hline Uji Coba Perorangan & Kemenarikan & 4 & $80 \%$ & Sangat Layak \\
& Penyajian Materi & 4,7 & $94 \%$ & Sangat Layak \\
& Tampilan Penulisan dan & 4,43 & $87 \%$ & Sangat Layak \\
& penggunaan bahasa & & & \\
& Total keseluruhan & 4,34 & $87 \%$ & Sangat Layak \\
Uji Coba Kelompok & Desain Tampilan & 4,5 & $90 \%$ & Sangat Layak \\
Kecil & Tampilan Gambar & 4,7 & $94 \%$ & Sangat Layak \\
& Manfaat Soal & 4,8 & $96 \%$ & Sangat Layak \\
& Total keseluruhan & 4,7 & $93 \%$ & Sangat Layak \\
Uji Coba Lapangan & Kejelasan dan isi & 4,56 & $91 \%$ & Sangat Layak \\
& Keberadaan soal & 4,67 & $93,4 \%$ & Sangat Layak \\
& Tujuan pembelajaran & 4,65 & $93 \%$ & Sangat Layak \\
& Kemudahan penggunaan & 4,85 & $96 \%$ & Sangat Layak \\
& Total keseluruhan & 4,64 & $93 \%$ & Sangat Layak \\
\hline
\end{tabular}

Berdasarkan rekapitulasi hasil uji coba soal open ended pada tabel 2 diperoleh persentase keseluruhan uji coba perorangan $87 \%$, persentase keseluruhan uji coba kelompok kecil 93\% dan persentase keseluruhan uji coba lapangan 93\%.

Setelah soal open ended dinyatakan valid, soal open ended diimplementasikan di kelas sesungguhnya, yaitu kelas VIII SMPN 9 Kota Jambi, dengan jumlah siswa 26 orang. Soal tersebut diujicobakan pada tanggal 4 April 2019.

Tahap evaluasi (evaluation) ini melakukan analisis data penelitian yang diperoleh dari pengisian instrumen penilaian. Tujuan dari analisis data ini adalah untuk mengetahui kelvalidan, reliabilitas soal, tingkat kesukaran soal dan daya beda soal. Untuk hasil analisis kelvalidan tiga soal dengan validitas tinggi, satu soal sangat tinggi dan satu soal rendah. hasil reliabilitas soal dengan nilai 0,6375 dengan kriteria tinggi, sedangkan pada tingkat kesukaran soal tiga soal terkategorikan mudah dan dua soal dengan kriteria sedang dan pada daya beda soal tiga soal dengan kriteria cukup dan 2 soal dengankriteria baik, berdasarkan hasil rekapitulasi kelvalidan, reliabilitas soal, tingkat kesukaran soal dan daya beda soal dapat disimpulkan bahwa satu soal tidak terpakai, dua soal dipakai tetapi perlu diperbaiki dan dua soal dipakai.

Penelitian pengembangan terdapat beberapa keterbatasan penelitian yaitu (1) Dalam melakukan pengembangan ini prosesnya cukup lama; (2) Pengembangan soal open ended hanya pada satu pokok bahasan yakni bab materi lingkaran kelas VIII SMP; (3) Biaya yang dikeluarkan dalam pengembangan cukup mahal; (4) Terbatasnya waktu dalam melakukan penelitian membuat penelitian hanya pada satu sekolah yaitu SMP Negeri 9 Kota Jambi. Dengan mengambil 3 kelas subjek dimana masing-masing kelas subjek dilakukan untuk beberapa tahapan uji coba yaitu uji coba perorangan dalam satu kelas subjek hanya diambil 3 orang responden, uji coba kelompok kecil dalam satu kelas subjek hanya diambil 6 orang responden dan uji coba lapangan dalam satu kelas subjek dilibatkan seluruhnya. Jika setiap tahapan uji coba dilakukan di dalam kelas subjek secara menyeluruh hasilnya belum tentu sama; (5) Penelitian ini pada soal yang dibuat hanya mampu mengukur kemampuan berpikir kreatif indikator fluency dan flexibility, sedangkan indikator novelty belum terlihat.

\section{SIMPULAN DAN SARAN}

Berdasarakan hasil dari pembahasan diperoleh kesimpulan yaitu proses pengembangan produk soal open ended dilakukan dengan lima tahap pengembangan model ADDIE dan kualitas soal diproleh hasil yaitu: (1) berdasarkan hasil validasi soal yang telah dilakukan kepada satu orang validator yaitu ahli materi diperoleh bahwa persentase keseluruhan $87 \%$ sehingga menunjukkan soal open ended dinyatakan valid setelah dilakukan beberapa revisi dan perbaikkan. (2) berdasarkan hasil uji coba 


\section{$\pi$ (Phi)}

soal open ended diperoleh bahwa persentase keseluruhan uji coba perorangan, uji coba kelompok kecil, dan uji coba lapangan yaitu $87 \%, 93 \%, 93 \%$. (3) berdasarkan hasil dari rekapitulasi rekapitulasi kelvalidan, reliabilitas soal, tingkat kesukaran soal dan daya beda soal dapat disimpulkan bahwa satu soal tidak terpakai, dua soal dipakai tetapi perlu diperbaiki dan dua soal dipakai.

Berdasarkan simpulan penelitian, disarankan agar; (1) guru dapat menjadikan soal open ended yang telah dihasilkan sebagai tambahan bahan ajar, (2) siswa dapat menjadikan soal-soal tersebut sebagai bahan latihan dan agar terbiasa menyelesaikan soal-soal sejenis dalam meningkatkan kemampuan berpikir kreatif, (3) peneliti lain dapat menjadikan hasil penelitian ini sebagai bahan masukan.

\section{DAFTAR PUSTAKA}

Akbar, Sau'dun. (2013). Instrumen Perangkat Pembelejaran. Bandung : PT Remaja Rosdakarya.

Arikunto, S. (2010). Prosedur Penelitian Suatu Pendekatan Praktik. Jakarta: Rineka Cipta.

Gafur, A. (2012). Desain Pembelajaran. Yogyakarta: Ombak.

Haris, Jihad. (2012). Evaluasi Pembelajaran. Yogyakarta: Multi Pressindo.

Hasratudin. (2014). Membangun Karakter Melalui Pembelajaran Matematika. Jurnal Pendidikan Matematika Paradikma, (6)2.

Hidayat, S. (2013). Pengembangan Kurikulum Baru. Bandung: PT Remaja Rosdakarya.

Iskandar. (2009). Psikologi Pendidikan Sebuah Orientasi Baru. CipayungCiputat: Gaung Persada (GP).

Lestari, Karunia Eka dan Mokhmmad Ridwan. (2015). Penelitian Pendidikan Matematika. Bandung: PT. Refika Aditama.

Mardayanti, Elva. (2016). Pengembangan Soal Open Ended Menggunakan
Konteks Sumatera Selatan Materi Sistem Persamaan Linear Dua Variabel Kelas X SMA. Jurnal Pendidikan Matematika, 10(1), 2.

Najwa, F. (2016). Pengembangan Soal Open

Ended Untuk Mengukur Kemampuan

Berpikir Tingkat Tinggi Siswa Pada

Materi Gejala Pemanasan Global.

Tesis. Semarang: Program

Pascasarjana Pendidikan Universitas

Negeri Semarang.

Piskurich, George M., Beckschi, P \& Hall,

Brandon. (2003). The ASTD

Handbook Of Training And Delivery. London: McGraw-Hill.

Sudjana. (2005). Metode Statistika. Tarsito: Bandung.

Sugiyono. (2018). Metode Penelitian Pendidikan Pendekatan Kuantitatif, Kualitatif dan $R \& D$. Bandung: Alfabeta.

Siswono, Tatag Yuli.E. (2018). Pembelajaran Matematika Berbasis Pengajuan dan Pemecahan Masalah. Bandung: PT Remaja Rosdakarya.

Tegeh, dkk. (2014). Model Penelitian Pengembangan. Yogyakarta: Graha Ilmu.

Trianto. (2007). Model Pengembangan Terpadu dalam Teori dan Praktek. Surabaya: Kencana Prenada Media Group.

Wahidmurni, dkk. (2010). Evaluasi Pembelajaran Kompetensi dan Praktik. Yogyakarta: Nuha Litera.

Wahyuni, A, \& Abadi, A. (2014). Perbandingan keefektifan pembelajaran cooperative learning type STAD dan type TPS pada pembelajaran bangun ruang siswa SMP. Jurnal Riset Pendidikan Matematika 5(2), 164-175.

Widyoko,. Putro, E. (2017). Evaluasi Program Pembelajaran Panduan Praktis Bagi Pendidik dan Calon pendidik. Yogyakarta: Pustaka Belajar. 
Yuliana, E. (2015). Pengembangan Soal Open Ended Pada Pembelajaran MatematikaUntuk Mengidentifikasi Kemampuan Berpikir Kreatif Siswa. Jurnal Pendidikan Matematika, 171.

Yusuf, M. (2009). Pengembangan Soal-Soal Open Ended Pada Pokok Bahasan Segitiga dan Segiempat Di SMP. Jurnal Pendidikan Matematika 3(2), 50-51. 